\title{
Developmental dyscalculia, gender, and the brain
}

\author{
Varda Gross-Tsur, Orly Manor, Ruth S Shalev
}

\section{Background}

Developmental dyscalculia is a primary cognitive disorder of childhood affecting the ability of an otherwise intelligent and healthy child to learn arithmetic. ${ }^{1}$ Preliminary evidence indicates that developmental dyscalculia is seen in $5-6 \%$ of normal children ${ }^{23}$ and is as prevalent as developmental dyslexia or the attention deficit hyperactivity disorder.' One of the classifications of developmental dyscalculia subdivides dyscalculia to: (1) alexia and agraphia for numbers, (2) spatial dyscalculia, (3) anarithmetia (impairment of calculation per se), (4) attentionalsequential dyscalculia, and (5) mixed type. Rourke and Finlayson used associated learning disabilities as a basis for their two group classification of dyscalculia: (1) reading, writing, and arithmetic equally impaired and (2) impaired arithmetic but reading and writing average or above. ${ }^{5}$ Kosc, however, emphasised the brain based nature of dyscalculia and defined it as 'a structural disorder which has its origin in a genetic or congenital disorder of those parts of the brain that are the direct anatomicophysiological substrate of the maturation of the mathematical abilities'. ${ }^{2}$

Underachievement in arithmetic is also seen in children with low intellectual ability, ${ }^{6}$ adverse psychological factors, and low socioeconomic status $^{37}$ as well as in children with neurological disorders. In fact, developmental dyscalculia is the most frequently encountered learning disability in children with epilepsy, ${ }^{8}$ fragile $\mathrm{X}$ carriers, Turner's syndrome, and phenylketonuria.' It is also a major symptom in developmental disorders of childhood such as the attention deficit hyperactivity syndrome, ${ }^{10}$ the developmental Gerstmann's syndrome, ${ }^{11}$ and the developmental right hemisphere syndrome. ${ }^{12}$ Moreover, there appears to be an unusually high prevalence of developmental dyscalculia in girls. In this article we will focus on the neurological and developmental disorders associated with dyscalculia and discuss evidence for the apparent sex difference in its occurrence.

Neuropediatric Unit, Shaare Zedek Medical Center, Jerusalem, Israel Varda Gross-Tsur Ruth S Shalev

Braun School of Health and Community Medicine, Hadassah University Hospital, Jerusalem, Israel Orly Manor

Correspondence to: Dr Varda Gross-Tsur, Neuropediatric Unit, Shaare Zedek Medical Center, POB 3235, Jerusalem, Israel 91031. of epileptic children receive some form of educational support during their school careers. ${ }^{8}$ Several studies reported that the academic skill most impaired in these children is arithmetic. ${ }^{13}$
Aldenkamp reported that children in the 12-18 year age group had the most difficulties with mathematics. ${ }^{14}$ Seidenberg et al studied the academic achievement of 122 children ages 7-15 years and found that this group was making less academic progress than expected for their age and level of intelligence quotient (IQ); academic deficiencies were greatest in the area of arithmetic followed by spelling, reading comprehension, and word recognition skills. ${ }^{15}$ It has been postulated that the 'speed factor type' of learning disability in epileptic children was found to be related to underachievement in arithmetic. ${ }^{8}$ Early age of seizure onset, age of the child, increased lifetime total seizures, and the presence of multiple seizure types (especially tonicclonic and absence) were associated with poor arithmetic achievement scores. ${ }^{15}$ The mechanisms by which epilepsy may interfere with learning ability are multifactorial and include many of these same factors, for example the type (generalised seizures more than partial seizures) and number of seizures, the clinical syndrome involved, age of seizure onset, subclinical epileptiform activity, and the effect of antiepileptic drugs. ${ }^{815} 16$

Another syndrome in which dyscalculia appears is phenylketonuria, an inborn error of metabolism in which the fundamental defect is the absence of phenylalanine hydroxylase. Dietary manipulation prevents mental retardation in most cases but these children still have a raised rate of cognitive and behavioural problems. Their learning profile is characterised by difficulties in mathematics and symptoms of the attention deficit hyperactivity disorder. Reading is acquired normally. Dietary control may affect cognition perhaps by alteration of dopamine concentrations. ${ }^{9}$

\section{Developmental dyscalculia and developmental} disorders

Attention deficit hyperactivity disorder is defined as a disorder of inappropriate inattentiveness, impulsivity, and hyperactivity, ${ }^{1}$ and is diagnosed in clinical practice when a sufficient number of descriptors listed in the Diagnostic and Statistical Manual of Mental Disorders Third Edition, Revised criteria fit the patients. This disorder is frequently encountered in the normal population and these children are likely to experience difficulty in arithmetic, even if they acquire reading and spelling skills at an age appropriate pace. ${ }^{10}$ As there are no biological markers for the condition, Shaywitz and Shaywitz utilised the depressed scores on four 
Wechsler intelligence scale for children - revised (WISC-R) subtests: arithmetic, coding, information, and digit span as a supplementary diagnostic test. ${ }^{17}$ Arithmetic underachievement, in their opinion, is part of the definition of most children with attention deficit hyperactivity disorder. Thus it is not surprising that children who underachieve in mathematics are characterised by attention deficits and perceptual motor problems. ${ }^{18}$ Furthermore up to $50-80 \%$ of children with attention deficit hyperactivity disorder have learning disabilities, including dyscalculia. ${ }^{19}$

Another brain developmental disorder in which developmental dyscalculia is one of the major characteristics is the right hemisphere syndrome. Weintraub and Mesulam described a group of patients with a behavioural syndrome beginning in early life, characterised by emotional and interpersonal difficulties, visuospatial disturbances, inadequate paralinguistic communication, and neurological evidence of right hemisphere dysfunction. ${ }^{12}$ In their patients dyscalculia was demonstrated in those with average intellectual capacity and non-dyslexic learning disabilities. Other children with right hemisphere syndrome showed a profound inability to conceptualise numerical quantities, while symbol recognition and production were both preserved.' Weintraub and Mesulam suggested that acquisition of number concepts requires the participation of neural mechanisms of both hemispheres and may also be disrupted by early right hemisphere dysfunction. ${ }^{12}$ Using average evoked potentials during a neurometric battery (psychometric tests developed to avoid linguistic and cultural constraints), John et al were able to show that children with isolated arithmetic underachievement had specific and consistent $F$ ratio patterns in the $300-500 \mathrm{msec}$ latency domain on the right hemisphere, differing significantly from patterns of children with other learning disabilities or normal subjects. ${ }^{20}$ Evidence has also been presented for visuospatial dysfunction as one of the prerequisites for developmental dyscalculia. ${ }^{5}$

Developmental dyscalculia is a major criterion necessary to diagnose the developmental Gerstmann's syndrome, the others being finger agnosia, right-left disorientation, and dysgraphia." The neurophysiological substrate is thought to be localised to the left inferior parietal lobe. Kinsbourne and Warrington reported seven children with developmental Gerstmann's syndrome and emphasised the profundity of their arithmetical difficulties." Three of their cases were not able to do simple additions despite good comprehension of number concepts.

\section{Developmental dyscalculia and gender}

Whereas isolated learning disabilities other than developmental dyscalculia are more common in boys, ${ }^{1}$ developmental dyscalculia is more prevalent in girls with epilepsy, sex chromosome aneuploidies, and in female carriers of fragile $X .{ }^{9}$ The carriers of fragile $X$, heterogenous for the fragile site, demonstrate a broad spectrum of behavioural and cognitive dysfunction. ${ }^{9}$ Kemper et al reported a specific cognitive profile in female carriers of fragile $\mathrm{X}$ with a characteristic combi- nation of low arithmetic, digit span, and block design subtest scores on the WISC-R. ${ }^{21}$ More detailed neuropsychological testing demonstrated visuospatial dysfunction and behavioural and emotional problems that were all suggestive of a right hemisphere developmental impairment. The authors speculate that the presence of the fragile $X$ gene causes a specific set of focal deficits with a spectrum of clinical involvement. Turner's syndrome, a chromosomal aneuploidy of $45 \mathrm{X}$, consists of small stature, gonadal dysgenesis, transient congenital lymphoedema, and dysmorphic features. Girls with this syndrome have problems in arithmetic and handwriting. These girls do better on verbal tests relative to their achievement on performance and numerical tests. Right parietal lobe dysfunction, possibly related to the basic chromosome defect, is postulated as the cause of the cognitive impairment. ${ }^{22}$ Boys, on the other hand, with sex chromosome aneuploidies have increased risk for reading disabilities. ${ }^{9}$

Whereas developmental dyslexia and attention deficit hyperactivity disorder are more prevalent in boys with a ratio of 3-6:1,' developmental dyscalculia seems to affect both sexes more equally..$^{23}$ Arithmetic testing on 100 normal boys and 99 normal girls did not demonstrate differences in gender between the lower scoring children (lower $10 \%$ of sample) and the rest of the group. ${ }^{25}$ In the reports on the developmental right hemisphere syndrome there were equal or greater numbers of women than men. ${ }^{1226}$ These sex differences in learning disabilities are most apparent in the extreme cases of sex anomalies, such as Turner's syndrome or the supernumerary X syndromes. Speculations concerning sex differences in brain organisation and cognitive function resulting from hormonal influences on prenatal guidance of neuronal migration and neuronal connections have been entertained. ${ }^{27} 28$ Geschwind and Galaburda suggested that gonadal hormones, especially testestorone, may influence the development of anomalous brain dominance and favour talents associated with superior development of certain regions in the right hemisphere. ${ }^{27}$ Such hormonal influences could impact on future acquisition of arithmetic skills in normal boys and girls and have important determining effects for developmental dyscalculia.

The data regarding hemispheric lesions in children and mathematical abilities is contradictory. Whereas dyscalculia was noted as the only major neuropsychological deficit associated with impaired language in left hemisphere lesioned children, arithmetic achievement has been correlated with lack of right hemisphere impairment. In another study, arithmetic impairment was not a discriminatory factor between left or right hemisphere lesioned children. ${ }^{29}$ However, developmental dyscalculia is a major symptom of developmental right hemisphere syndromes and others in which visuospatial functions are impaired, for example Turner's syndrome, fragile X carriers, etc.

If developmental dyscalculia is the result of developmental hemispheric dysfunction, one could speculate that the 'cognitive crowding' phenomenon might explain the genesis of the 
symptomatology. ${ }^{30}$ Thus, the development of language in the right hemisphere would take priority over acquisition of other cognitive skills specific to this hemisphere including arithmetic function. Another hypothesis that could explain the selective development of developmental dyscalculia in children with genetic disorders is the asynchronous growth of the hemispheres in intrauterine life. There is an alternating right to left gradient in the embryological emergence of the cerebral hemispheres. According to this neuroembryological theory, later maturing brain structures show greater plasticity than earlier maturing regions. ${ }^{31}$ If the effects of the genetic disorder were so programmed as to disrupt brain development during the relative accelerated growth of the right hemisphere but not the left, one could speculate that the child would develop normal cognitive skills associated with the left hemisphere but not the right. Furthermore, in early childhood, the right hemisphere develops faster than left and is responsible for the child's prelinguistic learning. Therefore congenital dysfunction or arrest of the right hemisphere during development can be potentially deleterious to the child's early cognitive development. ${ }^{32}$

\section{Conclusion}

While developmental reading problems are primarily related to left hemisphere dysfunction, dyscalculia is associated with dysfunction of both hemispheres with a significant contribution from the right hemisphere. As girls are presumably more dependent on verbal cognitive processes and are superior to boys in this type of cognitive function, they may be more prone to learning disabilities that depend on the right hemisphere. This would explain the relatively large number of normal girls, and those with genetic and sex chromosome defects affecting right hemisphere functions, who have developmental dyscalculia.

Supported by a grant from the Office of the Chief Scientist, Israel Ministry of Health.

1 American Psychiatric Association. Diagnostic and statistical manual of mental disorders third edition, revised. Washington DC: APA, 1987.

2 Kosc L. Developmental dyscalculia. Fournal of Learning Disabilities 1974; 7: 46-59.

3 Gordon N. Children with developmental dyscalculia. Dev Med Child Neurol 1992; 34: 459-63.

4 Badian NA. Arithmetic and nonverbal learning. In: Myklebust HR, ed. Progress in learning disabilities. Vol 5. New York: Grune and Stratton, 1983: 253-64.

5 Rourke BP, Finlayson MAJ. Neuropsychological significance of variations in patterns of academic performance: verbal and visual-spatial abilities. 7 Abnorm Child Psychol 1978; 6: and visual-33.

6 Gaddes $W$. Neuropsychological basis of problems in writing, spelling and arithmetic. Leaming disabilities and brain function: a neuropsychological approach. 2nd Ed. New York: Springer, 1985: 355-69.

7 O'Hare AE, Brown JK, Aitken K. Dyscalculia in children. Dev Med Child Neurol 1991; 33: 356-61.

8 Aldenkamp AP, Alpherts WCJ, Dekker MJA, Overweg J. Neurophsyclological aspects of learning disabilities in epilepsy. Epilepsia 1990; 31 (suppl 4): S9-20.

9 Pennington BF. Genetics of learning disabilities. Semin Neurol 1991; 11: 28-34.

10 Ackerman PT, Anhalt JM, Dykman RA. Arithmetic automatization failure in children with attention and reading disorders: associations and sequela. Fournal of Learning Disabilities 1986; 19: 222-31

11 Kinsbourne M, Warrington E. The developmental Gerstmann syndrome. Arch Neurol 1963; 3: 490-501.

12 Weintraub S, Mesulam MM. Developmental learning disabilities of the right hemisphere. Arch Neurol 1983; 40: 464-8.

13 Ross EM, West PB. Achievement and problems of British eleven year olds with epilepsy. In: Meinardi H, Rowan AJ, eds. Advances in epileptology; psychology; pharmacotherapy and new diagnostic approaches. Amsterdam: Lisse Berwyn Swets and Zeitlinger, 1978: 34-7.

14 Aldenkamp AP. Epilepsy and learning behavior. In Parsonage M, Grant RHE, Craig AG, Ward AA Jr, eds. Parsonage M, Grant RHE, Craig AG, Ward AA Jr, eds. Advances in epileptology: the XIVth international
symposium. New York: Raven Press, 1983: 221-9.

15 Seidenberg $M$, Beck N, Geisser $M$, et al. Academic achievement of children with epilepsy. Epilepsia 1986; 27: 753-9.

16 Binnie CD, Channon S, Marston D. Learning disabilities in epilepsy: neurophysiological aspects. Epilepsia 1990; 31 (suppl 4): S5-8.

17 Shaywitz SE, Shaywitz BA. Diagnosis and management of attention deficit disorder: a pediatric perspective. Pediatr Clin North Am 1984; 31: 429-58.

18 Rosenberger PB. Perceptual-motor and attentional correlates of developmental dyscalculia. Ann Neurol 1989; 26: 216-20.

19 Golden SG. Role of attention deficit hyperactivity disorder in learning disabilities. Semin Neurol 1991; 11: 35-41.

20 John ER, Karmel BZ, Corning WC, et al. Neurometrics. Science 1977; 196: 1393-410.

21 Kemper MB, Hagerman RJ, Ahmad RS, Mariner R. Cognitive profiles and the spectrum of clinical manifestations in heterozygous fra $x$ females. Am $\mathcal{F}$ Med Genet 1986 23: 139-56.

22 Money J. Turner's syndrome and parietal lobe functions. Cortex 1973; 9: 387-93.

23 Shalev RS, Weirtman R, Amir N. Developmental dyscalculia. Cortex 1988; 24: 555-61.

24 Russell RL, Ginsburg HP. Cognitive analysis of children's mathematical difficulties. Cognition and Instruction 1984; 1 : mathem $217-44$.

25 Shalev RS, Manor O, Gross-Tsur V. The acquisition arithmetic in normal children: assessment by a cognitive model of dyscalculia. Dev Med Child Neurol (in press).

26 Tranel D, Hall LE, Olson S, Tranel NN. Evidence for a right hemisphere developmental learning disability. Develop mental Neuropsychology 1987; 3: 113-27.

27 Geschwind N, Galaburda AM. Cerebral lateralization : biological mechanisms, associations and pathology: II. A hypothesis and a program of research. Arch Neurol 1985; 42: $521-52$.

28 Netley C, Rovet $J$. The development of cognition and behavior in X aneuploids and other subject groups. In: Molfese DL, in X aneuploids and other subject groups. In: Molfese DL, Yegalowitz SJ, eds. Brain lateralization

29 Aram DV, Whitaker HA. Cognitive sequelae of unilateral lesions acquired in early childhood. In: Molfese DL, Segalowitz SJ, eds. Brain lateralization in children. New York: Guilford Press, 1988: 417-36.

30 Teuber HL. Recovery of function after brain injury in man In: Porter R, Fitzsimons DW, eds. Outcome of severe damage to the central neroous system. CIBA Foundation symposium 34. Amsterdam: Elsevier, 1975: 159-90.

31 Best CT. The emergence of cerebral asymmetries in early human development; a literature review and a neuroembryological model. In: Molfese DL, Segalowitz SJ, eds. Brain lateralization in children. New York: Guildford Press, Brain lateraliza 5 - 34 .

32 Semrud-Clikeman M, Hynd GW. Right hemispheric dysfunction in nonverbal learning disabilities: social, academia and adaptive functioning in adults and children. Psychol Bull 1990; 107: 196-209. 